\section{SUDDEN DEATH}

\author{
SUPPOSED TO
}

\section{SIMULATE POISONING BY OPIUM.}

NON-MEDICAL CORONERS.

\author{
To the Editor of THE LANCET.
}

SrR,-The insertion of the following case and observations in your valuable periodical will oblige your most obedient servant,

J. BernCAstie, M.R.C.S., \&c. \&c.

Croydon, June, 1843.

I was sent for on Tuesday, the 25th April, 1813 , at 6 a.m., to attend, on the part of the Croydon union, the illegitimate infant, six weeks old, of a pauper named Aldridge. The child was said to be in a fit. On my arrival at the house $I$ found the child dead. I had scarcely asked the mother and grandmother a few questions when the latter begged of me to examine the body and see that there had been no "misconduct" on their part. I thought that remark rather unusual, and examined the body more minutely, but could discover no marks of violence nor anything to lead me to suppose that the child had not died from natural causes. The face and body were quite pallid, and the mouth and eyes clused, without any unusual appearance.

A few hours afterwards, Mr. Smith, the registrar of deaths, sent to know whether an inquest would be required, as he had heard it reported by the neighbours that the child had died by unfair means. The inquest was consequently ordered, and thinking that I might elicit from the parties a few more points concerning the case, $I$ called again in the afternoon, seven hours after death had taken place, and found the body laid out. $I$ requested that the clothes should be taken off, and to $\mathrm{my}$ great surprise I observed the head, trunk, and extremities, to be covered with livid patches of ecchymosis, of a large size, pretty general all over the body. Knowing this cadaveric appearance so soon after death to be one of the common results from poisoning by opium, and having seen it in several cases that had terminated fatally, my attention was immediately directed into that channel, and $I$ asked the friends whether they had given the child any syrup of poppies, Godfrey's cordial, of laudanum, but they stoutly denied having given anything at all.

After cross-examining them pretty closely, I learnt that the child, otherwise remarkably healthy, had been for the last few days uu. commonly fretful, and particularly so on the Sunday; that on Monday he became rery drowsy, and slept all day and night without intermission, until early on the Tuesday morning, when it was suddenly seized with the convulsive fits that carried it off, and to relieve which had been called in.
The history of the case, coupled with the appearance of the body after death, being, as every medical man well knows, exactly those of poisoning by opium, the impression on my mind at the time was that the child might have died from the effects of that drug, or some of its compounds, either given intentionally or in an overdose through ignorance. The child being illegitimate might have also tended to strengthen the first suspicion. In fact, had the child been known to have died from opium the appealances above named would be all that one would expect to find without an autopsy.

Well, what did Mr. Carter, the coroner for Surrey, do? Instead of being guided by the medical evidence, and using it as the means to come at the truth, he at once turus round upon me and wishes to persuade the jury that there ale no grounds whaterer for presuming that the child had died from any other than natural causes! That he had frequently seen the livid appearance of the skin, which always arose from persons lying after death; that infants frequently died from apoplexy, and the like trash; that, besides, it was absurd to suspect that anything had been given when the mother and two other respectable witnesses swore to the contrary; that they being respectable people (all three paupers, and interested parties) be was bound to believe them on their oath, and that he did not think a post-mortem neces. sary, as there was not the slightest tittle of evidence to prove that anythiug in the shape of narcotics had been administered! Now the chain of symptoms and circumstantial evidence throughout this case were so clearly those of death by opium, and so unlike death from any other infantile disease, that nothing but the grossest ignorance on medical subjects can excuse Mr. Carter for having so totally overlooked them and disregarded the suggestions of the medical witness. On the contrary, he so far forgut his duty that he actually, in summing up the case to the jury, endeavoured to throw a slur upon the medical witness by inferring that he had acted wrongly by at all exciting suspicions in a case where nothing whatever could warrant any person in supposing that the child had died from any other than natural causes.

But had a post-mortem taken place, and, in spite of the oaths of these three very respectable uitnesses, poison had been found in the child's stomach, annulling all doubt upon the subject, and such cases are not uncommon, would he have thought then so lightly of medical evidence?

The case was dismissed summarily, and all parties entrely exculpated from any blame, the verdict being, "Died from natural causes."

Now would not a medical coroner at once have fallen in with the views of the medical witness, and would not his attention have 
been seriously arrested upon the probability of poison in a case where all the circumstances were so well linked together as to raise rather more than a suspicion of guilt? Is it not generally by some vague unconnected facts that cases of poisoning are at first brought into notice? Before detecting the poison are there not premonitory and concomitant signs and circumstances that put one on the qui vive, and lead one to seek for it by further anatomical investigations? How, then, can any person not well acquainted, practically as well as theoretically, with this intricate branch of the profession, presume to offer his opinion on subjects of such importance that they may involve the life of a fellow creature? It is an anomaly that cannot exist any longer in a country that boasts of ranking first in civilization. The time must come, and come shorly it will, when none but medical coroners will be allowed to fill that high office, Until then, we must not be surprised to see doubtful cases smothered in a similar way to the one here cited by Mr. Carter, or any othel of his sapient non-medical colleagues.

** We do not think that Mr. Berneastle has selected a good case for illustrating his views. The law is not in a condition to justify coroners in ordering post-mortem examinations in all cases of sudden death, and if $\mathrm{Mr}^{\circ}$. Carter did not exercise some discretion on the subject, be would soon find out, at the Court of Quarter Session, to his cost, that he was making presents of fees to medical witnesses out of his own pocket. Whether the law is right in this respect, is another question. It must be obesed as it stands, good or bad. Most certainly a coroner would not be justified in having a body opened simply because it was that of an illegitimate child and the parent was pool. A more unjust and odious rule it would be difficult to adopt. The only other ground, in the present state of the law, for directing an examination in the case of Aldridge (judging from the statement of our correspondent) was the suspicion raised by the medical witness himself, from an external view of the body; and in reply to this we may observe that the data for that sus. picion were not well founded. Where Mr. Berncastle has seen one such body as he has described, our own experience has extended to scores, if not hundreds, and-to be brief where the occasion does not warrant an essay - we state that a medical witness may as well look at the outside of a block of colite limestone to judge whether an unfortu. nate toad is shut inside, as at the exterior of a dead body to pronounce whether the death has been produced by poison. Even a nonmedical coroner may arrive, by experience, at a well-grounded assurance of this fact, the authorities, in books, having written so many fables, instead of truths, on many of the most important points in medical jurispiadence.

\section{NEW ASTRINGENT PREPARATION.}

By digesting rhatany in sulphuric ether a brown extract is obtainable, perfectly soluble in distilled watel, and when placed on the tongue giving a sensation of great astringency, followed by heat and dryness. This extract, invented by a M. Tissier, of Lyons, has been employed with success in that city in passive hæmorrhages, particularly those consequent on non-contraction of the uterus, as after prolonged labours and miscarriages. It has also been used with advantage for leucorrhoea, blennorrhœa, gleet, $8 x$. The dose in which it has hitherto been employed is a tablespoonful of a mixture composed of from fire to ten grains of the extract in six ounces of some appropriate vehicle; in leucorrhoea, topical injections are recommended of from two to five grains of extract in a pint of barley-water. The presence of this preparation in the stomach gives rise, generally, to a sensation of heat in the epigastrium, though this rarely proceeds so fal as to become painful; great thirst, and a pulse often as full as in gastri. tis, also prevail. These symptoms are, however, transient, and readily quelled by lemonade of other mild drinks. Should the injection irritate the urethra too greatly, it is only necessary to suspend its use for a short time.-See Gazette des Iopitaux, June 6th ult.

Treatient of Sininal Pains in Chronic InTERMITTENT Fever. - The local pains along the vertebral column which have frequently been observed as an accompanying symptom of intermittent fevers, have been ascertained, by Dr. Gouzée, of Antwerp, through the medium of experimental pressure, to originate more particularly about the place of the third, fourth, and fifth dorsal vertebræ; and the remedial agents recommended by him, in obstinate intermittents attended by spinal pains, consist of cupping and leeches in the dorsal region, followed by counter-irritant plasters of tartarised antimony. The doctor informs us that this treatment has, in his hands, been very generally successful; but, says the "Gazette des Hôpitaux," we must confess that the method is so unusual that further experiment is necessary ere it can be recommended for general adoption. 